\title{
A Relação Universidade-Escola na Formação de Professores: Reflexões de uma Pesquisa-Intervenção
}

\author{
Luciana Lobo Miranda \\ Universidade Federal do Ceará, CE. Brasil. \\ Priscila Sanches Nery Oliveira \\ Universidade Federal do Ceará, CE. Brasil.
}

\author{
José Alves de Souza Filho \\ Universidade Federal do Ceará, CE. Brasil. \\ Suzana Kérzia Rocha Bezerra Sousa \\ Universidade Federal do Ceará, CE. Brasil.
}

Resumo: O presente trabalho traz uma reflexão crítica acerca da relação normalmente construída dentro dos muros acadêmicos a ser aplicada no cotidiano escolar. $\mathrm{O}$ artigo tem como objetivo discutir a formação de professores de educação básica como possível analisador da relação Universidade-Escola, a partir de uma pesquisa-intervenção realizada numa escola pública estadual no município de Fortaleza-CE. A partir das bases epistemológicas, políticas e éticas da pesquisa-intervenção, sobretudo da Análise Institucional e da Cartografia, discute-se a possibilidade de pesquisar COM a escola e não SOBRE a escola, enfatizando a micropolítica de seu cotidiano institucional. Com base na análise de implicação dos pesquisadores, os resultados envolvem a um só tempo, a reflexão acerca de como normalmente ocorre a entrada da universidade na escola como locusde pesquisa, e por outro lado, como a escola também acaba por habitar a universidade durante o processo de pesquisa. Tal discussão pretende contribuir para a formação de profissionais e pesquisadores $p s i$. Logo, analisam-se as reverberações da pesquisa-intervenção sobre as mudanças nas práticas pedagógicas dos professores participantes e na formação universitária dos psicólogos.

Palavras-chaves: Pesquisa-intervenção, Formação de Professores, Escola Pública, Universidade.

\section{The University-School Relationship in Teacher Training: Reflections of a Research-Intervention Project}

\begin{abstract}
This article poses a critical reflection on the relationship usually built inside the academic walls to be applied to the school routine. This article analyzes the training of basic education teachers as a possible analyzer of the University-School relationship, based on an intervention project carried out in a public school in the city of Fortaleza, Brazil. From the epistemological, political and ethical bases of intervention research, especially from Institutional Analysis and Cartography, we discussed the possibility of researching WITH a school and not ABOUT a school, while researching the micropolitics of its institutional daily life. Based on the researcher's analysis of implication, the results involve, on the one hand, a reflection on the entrance of the university into the school routine, and on the other, how a school can also inhabit a university. This discussion contributes to the training of both Psychology students and researchers. Thus, we presented an analysis of the intervention-research reverberations on the school teachers' pedagogical practices and also on the University's Psychology program.
\end{abstract}

Keywords: Intervention-Research, Teacher Training, Public School, University. 


\title{
La Relación Universidad-Escuela en la Formación de Profesores: Reflexiones de una Investigación-Intervención
}

\begin{abstract}
Resumen: El presente trabajo trae una reflexión crítica acerca dela relación normalmente construida dentro de los muros académicos a ser aplicada en el cotidiano escolar. El artículo tiene como objetivo discutir la formación de profesores de educación básica como posible analizador de la relación Universidad-Escuela, a partir de una investigación-intervención realizada en una escuela pública estatal en el municipio de Fortaleza-CE. A partir de las bases epistemológicas, políticas y éticas de la investigación-intervención, sobre todo del Análisis Institucional y de la Cartografía, se discute la posibilidad de investigar COM la escuela y no SOBRE la escuela, enfatizando la micropolítica de su cotidiano institucional. Con base en el análisis de implicación de los investigadores, los resultados involucran a la vez, la reflexión acerca de cómo normalmente ocurre la entrada de la universidad en la escuela comolocus de investigación, y por otro lado, cómo la escuela también acaba por habitar la universidad durante el proceso de investigación.Tal discusión pretende contribuir a la formación de profesionales e investigadores $p s i$. Luego, se analizan tanto las reverberaciones de la investigaciónintervención sobre los cambios en las prácticas pedagógicas de los profesores participantes como en la formación universitaria de los psicólogos.
\end{abstract}

Palabras clave:Investigación-intervención,Formación de Profesores,EscuelaPública,Universidad.

\section{Introdução}

O presente artigo tem como objetivo analisar a formação de professores de educação básica como possível analisador da relação Universidade-Escola, a partir de uma pesquisa-intervenção realizada numa escola pública estadual no município de Fortaleza-CE. Tendo como base a pesquisa "Pesquisando com Professores: A Relação entre mídia e cotidiano escolar" ${ }^{1}$, discutiremos questões que envolvem a formação permanente de professores, especialmente aquelas relacionadas aos desafios contemporâneos que o cotidiano escolar apresenta para as práticas pedagógicas docentes. Pesquisadores universitários, em especial os das áreas da educação e psicologia escolar-educacional, vão às escolas, por meios de pesquisas, extensões e estágios desenvolver ações junto a comunidade escolar, e mais especificamente à formação de professores de escola básica. São os discursos e acontecimentos que surgem da estreita relação entre universidade-escola que serão aqui discutidos.

A formação de professores encontra-se inserida nas políticas educacionais do país. Segundo Nacarato (2016), a Coordenação de Aperfeiçoamento de Pessoal de Nível Superior(Capes), com a Lei no 11.502 de 2007, passou "a ser responsável pela formação inicial e conti- nuada de professores da educação básica" (p. 707). São três os principais programas de atuação: 1- Programa Institucional de Bolsa de Iniciação à Docência (Pibid), projeto que visa à inserção de graduandos no contexto das escolas públicas, onde estudantes universitários desenvolvem projetos didático-pedagógicos junto aos professores da escola; 2- Observatório da Educação (Obeduc) que em parceria com a Capes, o Instituto Nacional de Estudos e Pesquisas Educacionais Anísio Teixeira (INEP) e a Secretaria de Educação Continuada, Alfabetização, Diversidade e Inclusão (Secadi) pretendem fomentar estudos e pesquisas em educação, com base na infra-estrutura das instituições de educação superior e as bases de dados no INEP; 3- E finalmente o Plano Nacional de Formação de Professores da Educação Básica (Parfor), programa que oferta turma especial de cursos de licenciatura para professores da rede básica que ora não possuam curso superior.

A autora afirma que a execução desses programas, seja com fins de pesquisas ou de formação, é operada pela parceria universidade-escola, especialmente, a relação entre pesquisadores-formadores com os docentes da rede básica: "Entendo que a parceria universidade-escola precisa ser uma construção coletiva, pautada no respeito e na abertura ao diálogo.

${ }^{1}$ Pesquisa financiada pela UFC através da bolsa Pibic-UFC e pelo Conselho Nacional de Desenvolvimento Científico e Tecnológico (CNPq) através de bolsas Pibic-CNPq e Bolsa Produtividade. Pesquisa aprovada no Comitê de Ética com Número do Parecer:1.332.793. 
Não há manual de orientação para fazê-la acontecer; ela é construída no processo" (Nacarato, 2016, p. 713).

Trabalhos recentes colaboram para a discussão dessa temática. Se no plano macro podemos delinear algumas ações, no qual a relação universidade-escola deva ser considerada como as políticas públicas anteriormente citadas, é no plano micropolítico que se promove toda uma "analítica das formações do desejo no campo social” (Aguiar,\& Rocha, 2007, p. 660). Nossa pesquisa se insere no âmbito micropolítico, pois não apenas as questões molares são consideradas, mas também as singularidades do cotidiano institucional constituem material de análise.

Outras pesquisas de cunho qualitativo têm discutido a relação universidade-escola. A pesquisa-ação de Coutinho, Folmer e Puntel (2014), operada por uma ação de extensão numa escola pública, tratou da discrepância e desconhecimento entre a produção da academia e falta de apropriação de professores para com as produções da universidade com relação às novas metodologias e novos conhecimentos pedagógicos. Sobre os resultados da formação, o grupo de professores reconheceu a importância dos bancos de dados de produções científicas, tanto como fontes de novas informações para os conteúdos escolares, como para acervo de novas metodologias a serem implantadas nas práticas pedagógicas. Os estudos de Freitas, Carvalho e Oliveira (2012) analisaram a própria formação dos professores da universidade quando vão pesquisar com professores da escola pública. Na pesquisa, os professores universitários entendem "os limites e os condicionantes de sua ação, trazendo à tona sua individualidade, o que implicava respeitar seu próprio tempo e seu grau de compromisso para com o projeto" (p.333). Dessa forma, na relação interinstitucional, a formação operou-se de forma conjunta, na medida em que os professores da educação básica discutiram suas dificuldades de desafios, e os professores universitários igualmente questionavam o excessivo do rigor lógico conceitual rotineiro da academia e a necessidade de maior flexibilidade de trabalho da universidade no trabalho conjunto com a escola.

Outro problema a ser destacado da formação continuada para professores da educação básica é a distância preocupante entre teoria e prática. Segundo Ludke e Boing (2012), cabe à universidade tentar resolver esse empecilho, com programas de pesquisa, a exemplo Pibid anteriormente citado, extensões e estágios que aproximam o futuro professor de edu- cação básica ao contexto escolar, principalmente, da escola pública. Ainda de acordo com esses autores, alguns fatores que contribuem como agravantes são: a dificuldade de lecionar e a linha tênue entre ensinar e aprender; o desencontro geracional, no qual se observa a delicada convivência entre grupos de cultura e tempo diferentes na escola; a discrepância de técnicas e práticas escolares com o contexto histórico; e a flexibilidade laboral, que se apresenta com um contraste entre o trabalho fictício e o trabalho real do professor, entre outros pontos.

Além das questões anteriores, há o problema da escassez de uma formação continuada e suporte para o profissional da educação. Como mostra Marli (2012), em seu artigo sobre políticas e programas de apoio aos educadores estreantes, é de extrema importância preparar o profissional educador, principalmente em início de carreira para a realidade laboral da escola, pois é notória a incongruência encontrada entre o que se deveria fazer e o que de fato se faz. O autor evidencia e denuncia o pouco suporte, acompanhamento e falta de avaliação da formação continuada dos professores. Ainda que algumas secretarias de educação brasileiras se esforcem para preparar seus mestres, a formação é pontual e descontextualizada, e enfrentam a dificuldade de constituir bons professores e, pior, de mantê-los no sistema público de ensino.

Por outro lado, os trabalhos de Dias (2011; 2012; 2015) discutem as pesquisas sobre formação continuada de docentes como um espaço de problematização. Orientada pela pesquisa-intervenção, seus trabalhos de formação continuada reivindicam um campo de criação e de experimentação no acompanhamento dos processos de intervenção dentro da micropolítica do cotidiano escolar. A autora discute, no âmbito da pesquisa-intervenção, a relação entre escola e universidade "como uma experiência modificadora de si, com a finalidade de constituir para si mesmo um modo de vida ético, estético e político" (Dias, 2015, p. 199). Esta pesquisadora aposta na perspectiva política da criação, de modo especial, pelo trabalho conjunto de entre saberes e instituições:

Pesquisa-intervenção, formação inventiva, produção de subjetividade, escola, universidade e mundo devem ser considerados como obras abertas, virtualidades em ressonâncias, constituidores de linguagem, de conhecimentos vivos, em devir tensionados entre formação e capaci- 
tação, entre passado e futuro, entre novidade e invenção (Dias, 2015, p. 205).

Corroboramos as ideias de Dias (2011; 2012; 2015) e em trabalhos anteriores discutimos a relação pesquisa-escola-juventude (Miranda, Cysne,\&Alves Filho, 2016a; Miranda, Oliveira, Shionga,\& Rodrigues, 2016b). Nestes, podemos perceber que o trabalho conjunto e dialógico entre os atores, especialmente pela negociação entre seus interesses, permitiu transformar a demanda de análise centrada nos alunos para uma discussão mais ampla que problematiza o cotidiano escolar.

Trabalhar os condicionantes institucionais na engrenagem da maquinaria escolar tem sido uma aposta para a formação do profissional em Psicologia que pretenda uma atuação no campo educacional. Desde os anos 1980, Patto (1984) discute a interface psicologia/educação, apostando numa perspectiva sociopolítica para a atuação $p s i$. Mais recentemente Heckert e Rocha (2012) e Machado (2014) dentre outros pesquisadores têm analisado respectivamente aspectos de medicalização e judicialização da escola e a necessidade de as práticas em Psicologia intervirem nos processos institucionais, considerando a própria formação como constitutiva do cotidiano escolar.

É nesta perspectiva que propomos uma pesquisa-intervenção com professores da rede pública. Mantendo o escopo de interesse acerca dos modos de subjetivação presentes na relação escola e mídia, (Miranda, 2015; Miranda et al., 2016a), foi proposto um curso de formação de professores. Não pretendíamos transformar o curso em mais um espaço de capacitação ou transmissão de informações. Nossa proposta aproximou-se das ideias de Bondia (2002) em que os espaços educacionais hoje devem resgatar a construção de locais onde os indivíduos possam passar por experiências:

Se a experiência é o que nos acontece e se o saber da experiência tem a ver com a elaboração do sentido ou do sem-sentido do que nos acontece, trata-se de um saber finito, ligado à existência de um indivíduo ou de uma comunidade humana particular; ou, de um modo ainda mais explícito, trata-se de um saber que revela ao homem concreto e singular, entendido individual ou coleti- vamente, o sentido ou o sem-sentido de sua própria existência, de sua própria finitude (p.27).

Reconhecemos que trabalhar com professores dentro da escola pública é uma oportunidade rara para pesquisadores e estudantes do curso de Psicologia, especialmente pela ausência de psicólogos na maioria das instituições educacionais públicas. A vivência no campo da escola é estratégica tanto para a formação de futuros psicólogos, quanto de futuros pesquisadores. Estarmos habitando o campo e interagindo com seus atores tornou-nos mais sensíveis às questões contemporâneas: o desafio de lidar com as novas configurações tecnológicas, a aproximação entre universidade e escola de forma não hierarquizada, e a formação continuada de professores na rede pública de ensino. Neste trabalho será dada ênfase às duas últimas questões.

Assim, nosso objetivo é discutir a construção da parceira universidade-escola mediante a formação continuada de professores, tendo como base dados de uma pesquisa-intervenção. Para atendê-lo, traremos, a seguir, a base teórico-metodológica que subsidiou nossas atuações. Posteriormente, a partir de nossa própria implicação no processo de pesquisa, discutiremos a construção do processo da pesquisa privilegiando, por um lado, questões que envolvem a entrada da universidade na escola locusda pesquisa e por outro, como a escola também acabou por habitar a universidade, contribuindo para a formação de profissionais e pesquisadores psi. Logo, sobre os resultados dessa construção, analisaremos tanto as reverberações da pesquisa-intervenção sobre as mudanças nas práticas pedagógicas dos professores participantes como na formação universitária dos psicólogos.

\section{Metodologia}

\section{O dispositivo Curso de Formação de Professor}

A necessidade de uma pesquisa-intervenção que trabalhasse diretamente com professores, na qual a própria formação docente se colocasse como dispositivo de análise, emergiu a partir dos resultados da pesquisa anterior: "Juventudes e Mídia: Um Estudo sobre Consumo, Apropriação e Produção de Mídia por Jovens Estudantes de Escola Pública de Fortaleza-CE”, realizada entre 2012 e $2014^{2}$. Ao analisar a rela-

${ }^{2}$ Pesquisa financiada pelo CNPq através de bolsas Pibic/CNPq, edital Ciências Humanas. 
ção entre jovens estudantes de duas escolas públicas de Fortaleza (uma profissionalizante e outra regular) e as mídias, sobretudo as digitais, observaram-se os tensionamentos entre os modos de subjetivação presentes nas mídias que primam pela dispersão oriunda da hiperconexão e àqueles exigidos pelo ambiente escolar, que demandam concentração e tentam, ora mediar, ora efetivamente tutelar, a relação dos estudantes com estes meios. O desencaixe entre corpos juvenis e o cotidiano escolar que nos fala Sibilia (2012) foi corroborado em nossa análise.

Imbuídos pelos questionamentos em saber como docentes perceberiam estas tensões identificadas nos resultados com os jovens, propomos a já citada pesquisa: "Pesquisando com Professores: A Relação entre Mídia e Cotidiano Escolar” voltada agora para os docentes. Iniciamos o trabalho na escola regular.

A Escola em questão, localizada num bairro da periferia de Fortaleza, assemelha-se em sua estrutura e seu cotidiano com tantas outras existentes no ensino público brasileiro: salas de aula, banheiros, Laboratório Educacional de Informática, sala de multimeios, sala de professores, secretaria, sala da direção e coordenação, biblioteca e cantina. Em 2015, a escola possuía aproximadamente 1.500 alunos (maioria moradora da região e oriunda de família de baixa renda) e 80 professores (muitos ensinam no ensino fundamental e no ensino médio) e 20 funcionários. A partir de 2016, a escola extinguiu o sexto ano e a matrícula começou a ser do sétimo ano em diante, indo até o terceiro ano do ensino médio. Nesse ano, a escola passou a ter 1.350 alunos, com 14 turmas distribuídas nos três turnos e quatro turmas de Educação de Jovens e Adultos (EJA).Trata-se de uma escola atravessada por uma rotina comum a tantas outras, mas singular nos seus processos, nos modos de subjetivação deste cotidiano. E é justamente no plano micropolítico, isto é, no "exercício de acoplamento das teorias e memórias locais" (Aguiar e Rocha, 2007, p. 662) que, como pesquisadores, pretendemos investigar.

Como na pesquisa anterior que privilegiou o trabalho não SOBRE os jovens, mas COM os jovens (Miranda et al., 2016a; 2016b), o desafio agora colocava-se em pesquisar COM professores através do dispositivo curso formação de professor. A pesquisa-intervenção teve um papel central na construção da nossa pesquisa, entendida como uma ruptura com o modo positivista de se fazer ciência (Aguiar, \& Rocha, 2007; Dias, 2012), e na qual o momento de pesquisar e de intervir se sobrepõe (Paulon, 2005). Na pesquisa-intervenção, o campo é um convite para implicação, de forma que possamos modificar o cenário e sermos modificados por ele: "O pesquisar COM se lança precisamente no desafio de desfazer e refazer certas fronteiras, e com isso, se engaja na aposta de fazer um mundo comum, mais heterogêneo, onde mais e mais atores contem" (Moraes, 2014, p. 134). Vale acrescentar que no espaço escolar pesquisar COM o ator-professor nos lança também outros desafios, pois diante da precarização laboral que atinge a profissão docente na atualidade, conforme vimos na seção anterior, o tempo para formação e reflexão acerca das ações cotidianas costuma ser escasso.

Corroboramos com Dias (2015, p.195) na necessidade de pensar a formação de professor como aposta ética, estética e política do trabalho docente, bem como lugar de problematização do cotidiano escolar e de produção de subjetividade, pois "uma formação inventiva, [...] se liga aos territórios escolares para provocar um exercício de colocar a atenção no presente e deformar, mais do que formar". Parafraseando Gilles Deleuze na sua relação com a filosofia, a autora afirma a necessidade de pensar a formação de professor mais como movimento do que escola. Em nosso trabalho esta postura se traduziu em produzir uma formação docente como espaço aquém e além de circulação de técnicas de ensino, mas onde o movimento e a invenção pudessem ter uma centralidade. No qual as distintas formas de ver, pensar, sentir a si mesmo e ao mundo laboral, sua própria relação com as mídias e as novas tecnologias pudessem ser discutidas e re-significadas.

A formação docente compreendida desta forma coloca-se no campo da pesquisa-intervenção que tem como base a Análise Institucional Francesa e a cartografia. A Análise Institucional engendrou o Conceito de Análise de Implicação (Loureau, 2004; Paulon 2005) que, na contramão da neutralidade, propõe-se a analisar as próprias condições da pesquisa em sua dimensão processual, incluindo o próprio lugar do pesquisador. Este muitas vezes acaba sendo objetivado por aquilo que pretendia objetivar: "fenômenos, acontecimentos, grupos e ideias" (Loureau, 2004, p.148). A Cartografia, por sua vez, propõe-se a habitar um território e acompanhar processos a fim de pesquisar os modos de subjetivação existentes no campo pesquisado (Kastrup, 2008; 2010). Trabalhando com o conceito de cartografia e de pesquisa-intervenção Paulon e Romagnoli (2010, p.96) esclarecem que: 
não é a técnica ou o enquadre do campo que define o caráter de pesquisa-intervenção. Senão a posição que o pesquisador ocupa nos jogos de poder, fundamentalmente sua implicação com a instituição do saber científico, e sua abertura para criar zonas de indagações, de desestabilização que possam favorecer ao coletivo aflorar.

Na pesquisa intervenção em questão o que produz e constrói a pesquisa é o entrelaçamento da rede heterogênea entre universidade, pesquisadores, professores e escola, compondo uma cena enunciativa da formação de professores, mediante práticas discursivas e não discursivas que ajudam a tecer uma certa composição da pesquisa. Tal composição deve ser problematizada em sua dimensão processual (Aguiar,\& Rocha, 2007). Estas práticas discursivas e não discursivas são analisadas à luz do pensamento de Foucault (2004), que trata o discurso não como representação da realidade, mas como constitutivo dela. Assim, nos interessam as práticas discursivas enquanto regimes de dizibilidade que, articuladas às práticas não discursivas enquanto regimes de visibilidade, formam o dispositivo de intervenção curso formação de professores. Dispositivo, pois, que, se por um lado constrange, condiciona e determina certas formas de dizer e ver a escola como território da pesquisa, também põe para funcionar acontecimentos, produz análise para além do próprio contorno da pesquisa (Miranda, 2014).

Os processos institucionais possuem uma centralidade e demarcam o contorno de cada pesquisa-intervenção gestada. Assim, levando em consideração o território em que habitávamos, repleto, por um lado, de excesso de trabalho e pouco tempo para atividades extracurriculares, e por outro, com expectativa de um espaço institucionalizado para o desenvolvimento da pesquisa, propomos um curso de extensão "Diálogos Escolares: Mídia e Cotidiano Escolar", sobre a relação escola-mídia, cadastrado em nossa instituição de origem e com garantia de certificação $0^{3}$. No referido curso, "a ideia era dar visibilidade à forma como as relações que compreendem estudantes, professores e mídia se evidenciam no cotidiano e criar um espaço apropriado com os professores de discussão e produção coletiva" (Montenegro, Miranda, Feitosa, Cardoso, Oliveira,\& Oliveira, 2016, p.82).

No curso-formação-dispositivo, refletimos com os 25 professores, a maioria efetivos e há muito tempo trabalhando na escola, sobre temas relacionados à educação e mídia na contemporaneidade. Discutimos a função da escola; os conflitos intergeracionais; as relações de poder e de resistência; as possíveis estratégias pedagógicas, dentre outras questões. Dentre os 25 inscritos estavam a diretora e os três coordenadores. Treze do sexo masculino e 12 do feminino. Todas as áreas de conhecimento estiveram representadas no curso, com professores da área de linguagem e códigos, ciências humanas, ciências da natureza e matemática. A maioria possuia pós-graduação completa e a idade variou entre 24 e 58 anos. Como fomos chamados a trabalhar em alguns momentos nos encontros pedagógicos da escola, outros professores acabaram por compor também alguns momentos da pesquisa. Assim, além dos 25 que estavam efetivamente inscritos no curso, tivemos mais 10 participantes da pesquisa de forma pontual, totalizando 35.

O curso foi organizado com a proposta de observações, entrevistas, discussões, oficinas e produção de vídeo sobre a relação escola e mídia num total de 64 horas, dividido em sete módulos presenciais (44 horas) ocorridos em sua maioria aos sábados e um módulo não presencial (20 horas) ${ }^{4}$. Todos os módulos presenciais foram filmados e transcritos.

Por meio de visitas frequentes, observações em sala de aula, escrita de diários de campo, conversas informais, reuniões de pesquisa, além dos módulos presenciais, fomos nos apropriando, habitando o território escolar. A cartografia, segundo Kastrup (2010), propõe alguns movimentos no funcionamento atencional do pesquisador: o rastro, o toque, o pouso e o reconhecimento atento. Levando em consideração ser a cartografia um método ad hoc, sem intenção de uma replicação destes movimentos, que na dinâmica

\footnotetext{
${ }^{3}$ O curso foi vinculado ao Programa de Extensão TVEZ: Educação para o Uso Crítico da Mídia. Alguns membros da pesquisa também fazem parte da equipe desta ação de extensão.

${ }^{4}$ Módulo I: A função social da escola na contemporaneidade e os desafios da docência; Módulo II: A relação entre a mídia, os modos de subjetivação e formas de expressão dos estudantes e professores; Módulo III: A mídiacomo objeto de análise, como estratégia pedagógica e como forma de expressão no cotidiano de sala de aula; Módulo IV: Usos do vídeo, do blog e/ou de outros recursos comunicacionais como estratégia pedagógica e forma de expressão; Módulo V: Usos e desusos do celular na sala de aula; Módulo VI: Oficina de Fanzine: Possibilidades pedagógicas; Módulo VII: Oficina de vídeo. Criação de um produto comunicacional: Tema relação escola e mídia. Módulo não presencial (atividades práticas ao longo do curso que envolveram observação, planejamento, execução e avaliação de atividades pedagógicas relacionadas a utilização de recurso de mídia na prática docente).
} 
da pesquisa, muitas vezes se sobrepõem, cremos que rastreamos o campo em nossas visitas e conversas informais. $\mathrm{O}$ toque se deu enquanto gesto inicial em toda a negociação para construção do curso de formação de professor, bem como nas observações em sala de aula que nos ajudaram a produzir o pouso, o aprofundamento em questões, de acontecimentos que nos desestabilizam, e que eram trabalhadas no curso, como lugar de reconhecimento atento, como recondução ao objeto para destacar seus contornos singulares. Todos estes momentos se performatizavam na restituição, em que aspectos observados no cotidiano eram registrados no diário de campo e retornavam para a formação, para dramatização, debate e análise com os professores (Montenegro et al., 2016). A ideia do pesquisar COM os professores envolveu produções coletivas que problematizaram o cotidiano escolar e sua relação com a mídia, gerando produtos criados pelos próprios professores, tais como fanzines e vídeos.

Ao longo de todo o processo, numa pesquisa realizada no espaço escolar, fomos interpelados sobre o lugar da universidade. Nas observações em sala de aula muitas vezes alunos e professores pareciam nos colocar no lugar de fiscais, outras vezes professores e gestores falavam estar extremamente gratos pela presença da universidade ali, levando seu saber científico para o "chão da escola". No processo de pesquisar-intervir, a relação entre universidade-escola foi se (des) construindo no próprio cotidiano de nossos (des) encontros. O conceito de analisador, cunhado pela Análise Institucional, parece-nos precioso para discutir este campo de relação, pois evoca fatos, acontecimentos, indivíduos, práticas que produzem análise. O analisador traz o impensado para além do que está posto e evidenciado no cotidiano institucional. Para Aguiar e Rocha (2007, p. 656) os analisadores:

funcionam como catalisadores de sentido, expõem o saber e o não saber de uma sociedade sobre si mesma e, poderíamos dizer, desnaturalizam o existente, suas condições, e, ao realizar análise, desestabilizam a cena natural de um cotidiano que nos parece estático.

Ausente como questão inicial, problematizar a relação universidade-escola construída em nossa pesquisa-intervenção passou a assumir lugar de destaque, de catalisador de sentido que atravessou todo o processo da pesquisa e que será debatido a seguir.

\section{Resultados}

\section{A universidade habitando a escola}

A professora do LEI me viu e disse que eu ficasse à vontade para entrar, explicando: "a escola é pública, é pra você chegar e entrar, fique à vontade"- e me acompanhou à sala da coordenação (Pesquisadora N.F., Diário de Campo).

Uma das primeiras atividades da pesquisa foi apresentarmos a proposta em forma de debate. $\mathrm{Na}$ ocasião fomos recebidos com interesse por vários professores dispostos a participar do curso. Estivemos reunidos com o núcleo gestor a fim de ajustar o planejamento do curso de extensão, tanto antes de iniciá-lo, como durante a execução. Inserimo-nos na rotina da escola para divulgarmos a proposta do curso. Habitávamos a sala de professores e o pátio. Aos poucos fomos recolhendo os Termos de Consentimento Livre e Esclarecido (TCLE) dos professores interessados. Num dos diários de campo iniciais escrevemos: "Deixamos os professores bem à vontade para assinar. Percebemos que os que assinaram se mostraram interessados, fazendo comentários positivos em relação à proposta" (Pesquisadores N.F e M.K, Diário de Campo). Logo que o grupo se formou, tivemos nosso primeiro encontro presencial. Nesse momento, apresentamos a estrutura programática, com sua ementa, módulos, metodologias e estratégias pedagógicas. A ideia de um curso com ementa, conteúdo e carga horária que pudesse contar na progressão funcional dos professores havia sido preconizada como estratégia por nós pesquisadores, como forma institucionalizada tanto do vínculo universidade-escola, quanto escola-secretaria de educação.

Desde o início percebemos a grande heterogeneidade do grupo de professores, que ficava claro nos distintos interesses para com o curso:

Prof. E.: Do meu ponto de vista o que eu vou ver é que vocês irão trazer os pontos positivos e eu quero ir contra a maré, eu quero ver os pontos negativos [referindo-se à relação escola e mídia].

Prof. A.: Bom dia, meu nome é A., sou professor de química, sou professor do laboratório de ciências...é...então, minha expectativa para o curso 
está mais relacionada com o fato do...eu sou fã de tecnologia...geração videogame... Essas coisas... sou ligado nessas coisas... mas em sala de aula, eu sou muito tradicionalista (Encontro do Curso) ${ }^{5}$.

Enquanto E. coloca a universidade como o lugar que leva o conhecimento para o espaço escolar, A. parece se ver num paradoxo entre sua vida pessoal, hiperconectado e sua prática docente, alheia às novas tecnologias, e que o curso poderá lhe ajudar a enfrentar.

Logo na semana seguinte, começamos as observações nas salas de aula. As primeiras foram marcadas por estranhamentos. Por um lado, os alunos questionaram sobre aqueles jovens não-fardados que estavam lá para observá-los. Os professores minimizavam as confusões esclarecendo que estávamos lá para observar a sala de aula e sua dinâmica. Entretanto, alguns ainda mantinham para conosco uma ideia de vigilância, como nestes trechos de diário de campo: "Ao entrar na sala fui apresentada como aluna da pesquisa da UFC e a professora falou aos seus alunos que não estava lá pra observá-los e sim a ela" (Pesquisadora G.F., Diário de Campo). Essas tensões nos convocavam a nos aproximarmos mais do grupo escolar, de modo especial, questionando o papel de especialista. Logo, tentamos constituir interações mais dialógicas e informais. Para construirmos esses vínculos, passamos a chegar com antecedência na escola, buscando conversar mais com os professores, em que trocávamos ideias sobre assuntos diversos da vida escolar, além do tema do curso. Em alguns momentos, os professores falaram da importância da parceria universidade-escola, especialmente para a formação dos graduandos em Psicologia:

Antes de entrarmos na escola, encontrei a professora sentada ao lado da sala e acabamos por ter uma conversa informal, na qual ela expôs sua opinião acerca da importância dessa troca entre escola e universidade. Segundo ela, é essencial que os acadêmicos sejam expostos a essa realidade da escola pública antes de se formarem, pois só assim serão capazes de respeitar as diferenças desse espaço, ao invés de se chocarem e rejeitarem o que é diferente do ambiente universitário (Pesquisadora P.S.N., Diário de Campo).
Alguns professores já haviam passado por experiências anteriores de pesquisas realizadas em outras escolas em que trabalhavam. No segundo encontro presencial, um jovem professor trouxe o seu estranhamento sobre a nossa perspectiva de construir uma parceria enquanto modo de trabalho. Em outras experiências, segundo ele, pesquisadores entravam na escola e além de não criar vínculos com a instituição, acabava por trazer outros problemas para a própria escola:

Prof. C: A gente até dizia lá no Rio [de Janeiro] que a gente odiava quando a universidade chegava na escola. Chegavam e diziam que tavaerrado isso. Eles não construíam nada. Eles só chegavam coletavam dados, publicavam e depois a secretaria de educação ligava brava, perguntava se vocês estavam fazendo isso e não sei o quê (Encontro do Curso).

Em vários momentos, os (des)encontros universidade-escola nos interpelavam. Marcados pelas relações de poder onde normalmente esta é subjugada, através de práticas discursivas e não discursivas que tendem a desqualificá-la, destilando verdades sobre a escola, professores e gestores mostravam por vezes seu incômodo. Certo dia na coordenação, uma das pesquisadoras viu um livreto sobre "Violência nas Escolas" e perguntou a um dos coordenadores sobre o material e se já havia sido utilizado. Este explicou que a publicação fazia parte de uma pesquisa feita por uma universidade, que havia convidado a escola para contribuir. Eles chegaram a aceitar e iniciar a pesquisa, porém, quando perceberam que o intuito dos pesquisadores era, basicamente, coletar dados, ou seja, produzir estatísticas e banco de dados sobre situações de violência na escola e no seu entorno, desistiram. Não queriam a escola enquadrada como violenta, sem qualquer contribuição para a melhoria da instituição.

Na contramão das situações citadas, tentávamos construir um ambiente de troca, que em nada se assemelhasse àquelas descritas pelos professores quando "visitadas" pela universidade. Corroborando com Heckerte Rocha (2012, p. 91), apesar de todo o discurso legitimador da falência da escola pública e de sua entrega ao sistema de gestão ligada à eficiência tecnicista e burocratizada, era preciso que esta relação ajudasse a potencializar processos de criação que também povoam o cotidiano escolar.

\footnotetext{
${ }^{5}$ Todas as falas aqui apresentadas foram gravadas e transcritas.
} 
De maneira especial, acreditávamos que, pelo espaço de encontros e diálogos, os próprios professores podiam reconhecer que não se encontravam sozinhos. Por isso, muitos encontros também se tornaram momentos de descarga das tensões vividas pelos professores. No início dos encontros predominava a catarse, configurando-se como espaço de desabafo do que viviam no cotidiano. Professor E: "99\% das escolas estão passando por isso, mas fica só na sala dos professores, no desabafo" (Encontro do Curso).

No entanto, a possibilidade de coletivizar algo que era inicialmente percebido como restrito a aspectos individuais era necessário, porém insuficiente como espaço de formação COM os professores. Como forma de potencializar reflexões e deslocamentos de sua prática docente, recorremos a dinâmicas, vídeos e dramatizações. A proposta de formação de professores calcada na construção conjunta de novas estratégias de práticas docentes também implicou sobre a formação de psicólogos cientes da importância dessas questões, enquanto futuros psicólogos com atuação no âmbito educacional:

Prof. R: Eu tenho achado o curso maravilhoso, todos os encontros. É, eu tô achando dinâmico e eu tô me observando aqui, observando vocês, como é interessante que cinco horas passaram mais rápido com todo mundo falando, do que uma pessoa falando e todo mundo calado, passou muito mais rápido. E o que eu acho bacana desses encontros é porque a gente fala e tá ouvindo respostas, há um diálogo. Não é uma coisa que a universidade veio e observou e a gente não sabe. Tá sendo construído alguma coisa aqui e eu tô muito feliz por isso. Não tem arrependimento.

Pesquisadora. L.L.M.: Eu também fico muito feliz por isso. A gente fica, né?

Pesquisador J.A.S.F.: Assim, eu vou falar como... eu vejo que tá havendo um diálogo. Está ajudando na minha formação como psicólogo. Ver vocês, ver a experiência de vocês em sala de aula. É uma coisa que eu tô aprendendo muito também. É uma coisa que eu gosto muito, é a educação(Encontro do Curso).

\section{A escola atravessando a universidade}

O lugar que o ensino superior, a instituição universidade, ocupa permitiu nos colocar num lugar de credibilidade privilegiada. Não sendo somente a universidade que se fez presente na escola nesse campo de descobertas, mas numa via de mão dupla, esta também nos constituiu como pesquisadores e como futuros profissionais de psicologia. Como afirma Dias (2015, p. 202), sobre a experiência de discentes na formação de professores:

Cada aluno de graduação habita o território da escola básica, ao mesmo tempo em que frequenta a universidade, e passa pelo menos 6 horas semanais no âmbito da escola básica. Os efeitos deste modo de se formar produzem movimentos e composições numa tessitura micropolítica.

Estar na sala de aula, a partir das observações, nos permitiu revisitar o nosso lugar de estudantes da escola básica, experienciando aquela realidade de forma distinta, agora como observadores, mas, ainda assim, carregada de significados que nossas histórias de vida constituíram. A distância que há entre ser aluno de escola e ser aluno de universidade se explicitou a partir da construção da pesquisa e da nossa inserção no campo. É como revisitássemos os bancos escolares e suas vicissitudes. Sua necessidade de silêncio e disciplinamento, mas também o compartilhar com professores e alunos um campo de encontro, de conhecimento e de saberes.

No grupo de pesquisa semanal compartilhávamos diários de campo, planejávamos e avaliávamos o curso em andamento, muitas vezes redimensionando estratégias de intervenção e mesmo conteúdos, sempre tentando nos afastar dos especialismos que tendem a silenciar o outro. A escola estava presente em nossos encontros semanais, revisitada em nossos diários de campo e em nossas análises.

Discutíamos as melhores estratégias para garantir o espaço de escuta de todos, em que não fosse a nossa fala que preponderasse. Porém, por vezes, éramos colocados, ou mesmo nos colocávamos no lugar de suposto saber. Uma dessas situações envolveu uma professora que estava presente de forma pontual, nos encontros pedagógicos, mas não fazia parte do curso. Aparentemente inquieta durante um de nossos encontros com a temática sobre o uso do celular em sala de aula, a professora pediu a palavra no debate e nos interpelou quanto à nossa posição acerca da proibição ou liberação do celu- 
lar. Segundo ela, parecia que estávamos a favor do uso, mas não estávamos sendo claros, portanto, pediu que nos posicionássemos. Ela trazia a importância de nossa fala como especialistas em educação e naquela situação era importante deixar clara nossa posição, como um possível, uma virtualidade, não como vontade de verdade.

Este encontro com a presença de professores que não faziam parte do curso produziu uma diversidade de posicionamentos acerca do uso do celular em sala de aula. Se aqueles que faziam o curso pareciam trazer questões mais propositivas, os demais mantinham um tom de catarse de problemas que parecia já "superado". Mais do que a necessidade que nossa fala se impor, o que nos incomodou na reunião do grupo de pesquisa para avaliação do dia foi a heterogeneidade do grupo de professores. A heterogeneidade que tanto discutíamos com os professores como condição salutar ao cotidiano de sala de aula, agora nos incomodava. Como diz Loureau (2004) acerca da importância da análise de implicação, somos objetivados por aquilo que pensamos objetivar. Ou seja, da mesma forma que os professores desejavam turmas mais homogêneas como condição de boa aprendizagem e que tantas vezes ponderávamos, nós estávamos igualmente incomodados com a vitalidade da heterogeneidade na divergência de posicionamentos. Não só a universidade interpelava a escola, mas a escola nos interpelava. Implicados no processo, isto foi colocado em análise.

A avaliação do curso se deu em todo processo. Era preciso que a escola nos atravessasse em nossa formação de pesquisadores, mediante constantes reflexões nos diários de campo partilhados pela equipe e por vezes discutidos com os professores:

Saímos da escola realmente modificados por tudo que aconteceu. Acredito que a vantagem de ter como norte a pesquisa-intervenção é que nunca podemos prever os resultados, jamais devemos nos acomodar e cada dia se apresenta como um desafio inteiramente distinto. Modificamos o campo e fomos, por ele, modificados(Pesquisadora P.S.N., Diário de Campo).

\section{Discussão dos resultados}

Ao longo do processo de formação, fomos surpreendidos por devolutivas como a de uma professora, relatando que quando começou o curso era um "zero das mídias". Mesmo com a presença das tecnologias, como celulares e computadores, na sua casa com seus filhos, não se apropriava desses recursos. Entretanto as coisas mudaram, pois havia adquirido um smartphone com whatsapp. Quanto à sua prática docente, perdeu receios sobre as tecnologias dentro da sala de aula:

Profa. F: Eu perdi mais esse medo...eu era contra o uso desse meio em sala de aula, quando eu via um aluno eu dizia "guarde o celular, não pode!". Agora, eu até peço pra que eles vejam a hora no celular, por exemplo. Assim, quero agradecer a vocês pela oportunidade (Encontro do Curso).

Outra devolutiva interessante, no tocante à influência do curso na prática dos docentes, foi observada na fala de um dos Coordenadores. Segundo suas observações, os professores cursistas estavam encaminhando menos alunos à coordenação, sobretudo com questões relacionadas ao uso do celular em sala:

Após o início desse curso, a gente percebeu que os professores que estão frequentando esse curso, eles estão minimizando os problemas dentro da sala de aula com celular [...]. Corriqueiramente, os professores que estão retendo celulares e que estão colocando para fora da sala de aula, são os professores que não estão fazendo o curso. $\mathrm{O}$ fato de eles [professores cursistas] estarem fazendo o curso está melhorando a relação deles (Coordenador P. Encontro do Curso).

Essas restituições acompanharam todo o processo, à medida que nossas próprias intervenções problematizavam as práticas pedagógicas que trazíamos para o curso. Segundo outra professora, a possibilidade de dialogar durante o curso viabilizou: "um leque de opções para serem discutidas em sala de aula. Tanto a questão do uso do celular quanto o uso de uma vídeo-aula. Como pegar o celular e gravar para produzir um trabalho. Então são muitas coisas que podem ser feitas" (Profa A. Encontro do Curso). Mais que trazer a técnica, o curso pretendia abrir possibilidades, trabalhar virtualidades, novos possíveis, construídos COM os professores.

Os professores ainda enfatizaram que os temas tratados pelo curso foram de grande riqueza e que poderiam ser agregados ao próprio currículo do ano 
letivo. Posicionamento muito importante para nós, pesquisadores da universidade, que não desejávamos que o curso fosse visto como algo a mais no cotidiano laboral dos professores, mas sim incorporado organicamente ao seu cotidiano, abrindo fissuras, provocando alguns desassossegos.

Pudemos notar a contribuição na função pedagógica com relação ao uso crítico da mídia, como no caso da professora de história que usou a linguagem do fanzine, aprendida e discutida no curso, numa de suas aulas. Alunos abraçaram a ideia e se engajaram no processo de ensino-aprendizagem. A experiência desta mestra é remetida no diário de campo das pesquisadoras:

Quando a aula acabou, R. nos conduziu até a sala dos professores para nos mostrar os fanzines produzidos por outras turmas. O que nos chamou atenção, de modo geral, foi que os alunos compraram a ideia e fizeram o trabalho de forma séria e empenhada. Pareciam gostar bastante da aula e encontrar alguém mexendo no celular se tornou mais difícil (Pesquisadora P.S.N e S.S, Diário de Campo).

Além das avaliações acerca do curso de forma processual, a equipe de pesquisa no encerramento aplicou um questionário anônimo e avaliativo sobre a formação e seus consequentes resultados na prática docente, com respostas tanto objetivas quanto descritivas. Segundo a avaliação, todos afirmaram que o curso de extensão atendeu suas expectativas: "Na verdade ultrapassou as expectativas, pois dialogou entre a Escola e a Universidade e praticou a interdisciplinaridade" (resposta descritiva). A maioria dos participantes afirmou que os conteúdos trabalhados tiveram influência, de alguma maneira, no exercício de sua prática docente. Além de trazer as mídias como instrumento a ser aplicado no programa didático, alguns afirmaram textualmente: "passei a compreender melhor sobre a dinâmica das mídias e redes sociais na vida das pessoas"; logo nas relações interpessoais por parte dos docentes "melhorou minha visão acerca do uso das mídias em sala de aula e o diálogo com os alunos".

Parte dos docentes salientou como mais marcantes as produções fruto das oficinas: "Fanzine e vídeo. Gosto de coisas práticas. Principalmente quando consigo entendê-las e executá-las". De modo espe- cial, o fanzine surpreendeu. Muitos não conheciam essa mídia, mas os impressionou "A produção do fanzine. Pois foi uma oportunidade de termos contato com uma mídia que não precisa de tanta sofisticação para acontecer". Também foi abordada a relação da equipe de pesquisa com a escola quando salientaram "O compromisso do grupo da universidade no desenvolver do curso".

Questionamos sobre a perspectiva metodológica adotada nas atividades do curso. A aprovação do curso por parte dos professores variou entre excelente $(91,6 \%)$ e boa. A metodologia foi ressaltada como dinâmica e aberta: "Não é tediosa, envolve os profissionais, abre espaço para a fala e para as trocas. As dinâmicas foram muito importantes, pois havia objetivo final". Também afirmaram que as intervenções feitas nas atividades do curso promoveram mudanças e transformações no espaço escolar, algo de novo para a instituição: "Foi a primeira pesquisa, na escola, que realmente teve impacto na rotina e na construção de um novo olhar sobre as mídias".

Apesar de a maioria considerar suficiente a carga horária do curso, alguns comentários salientaram que a disponibilidade de um tempo maior seria propício para outras atividades ou mesmo para aprofundar as já programadas: “Tivemos tempo suficiente para compartilhar experiências durante o curso. Mas se fosse maior não faltaria construção. Gostaria que o tempo para a produção do vídeo fosse um pouco maior".

\section{Considerações finais}

Segundo Aguiar e Rocha (2007), no campo do cotidiano, são travadas as questões micropolíticas nas quais pesquisadores encontram seus desafios de transformações das práticas discursivas e não discursivas que naturalizam costumes e modos de ser. Na presente pesquisa foram muitos os desafios suscitados no encontro escola-universidade. Por um lado, os professores e coordenadores de uma escola pública se abriram para um curso de extensão promovido por uma universidade também pública. Uma oportunidade de formação, em meio a carências de políticas de formação continuada na rede pública. Por outro lado, para a equipe de pesquisadores, se colocou o desafio de trabalhar com a escola, não para levar o saber acadêmico para além dos muros da universidade, como muitas vezes 
é vista a extensão, mas pautada numa relação de troca, de diálogo.

Sobre este último ponto, salientamos que as mobilizações do cotidiano da escola colaboradora da pesquisa implicaram na formação dos estudantes de Psicologia. A partir do Projeto Político Pedagógico do Curso de Psicologia de nossa instituição, privilegiamos a "formação de profissionais comprometidos com as transformações da realidade social e com a construção de saberes psicológicos, orientados por uma consciência e postura ético-políticas" ${ }^{\prime \prime}$. Baseados em tal perspectiva, as discussões geradas pelos acontecimentos experienciados ao longo da pesquisa, bem como os dilemas que nos deslocaram enquanto especialistas ao longo de nossas intervenções, implicaram na formação crítica dos estudantes. Cada (r)encontro com a escola, nós pesquisadores construímos uma (com)ciência e postura ética-política de que nossos saberes, ações e perspectivas implicavam diretamente na promoção de um cotidiano escolar autônomo, com responsabilidades sobre seus processos e engajado em sua transformação.

Logo, para além de uma oportunidade de pesquisa, as experiências suscitadas na micropolítica do cotidiano escolar ajudaram a construir a formação ética enquanto estudantes de graduação e pós-graduação em Psicologia. O caráter ético-político de nossa formação advém seja quando questionamos sobre nosso papel de especialista, quando nos colocamos numa postura de constante troca com a escola, quando nos colocamos no lugar de não saber sobre o outro. Estar na escola ajuda a performatizar nossa própria formação. Trata-se, assim, de problematizar os processos que mobilizam nossa subjetivação, especialmente dentro das relações de poderes e instituições da qual somos partícipes.

Acima de tudo, com as análises feitas sobre os resultados e suas discussões, podemos verificar que este desafiador trabalho com professores na rede pública de ensino configura-se um valioso campo de construção e inovação. O trabalho interinstitucional, especificamente, o encontro entre os saberes do cotidiano escolar e o saber da universidade não deixou de ter suas tensões e sensibilidade. Entretanto, a vivência no campo pelo fortalecimento dos vínculos por encontros dialógicos, possibilitou a formação de envolvidos, tantos dos professores cursistas como dos pesquisadores em formação. Segundo Dias (2015), momentos formadores como os acima descritos configuram novas perspectivas éticas, estéticas e políticas de produção de subjetividades nos envolvidos nos processos. Seria o que a autora chama de momentos de formação inventiva, nos quais antigas praticas pedagógicas e docentes são deformadas, deslocando atenção para novos espaços de formação. Motivados pelo interesse de pesquisar COM (Moraes, 2014), as rupturas que emergiram pelos (des)encontros entre universidade-escola possibilitaram que os envolvidos fossem (de)formados (Dias, 2015). Colocar constantemente a própria pesquisa em análise permitiu que o planejamento de cada módulo produzisse um desassossego constante em nós, favorecendo a aproximação do cotidiano escolar. De maneira especial, mesmo com suas limitações e dificuldades, encontramos nesses espaços ferramentas e parcerias para projetos e ações condizentes com suas próprias necessidades, mas também produzindo novas demandas?.

À medida que professores participantes analisavam os desafios envolvidos em suas práticas docentes, experimentavam as vicissitudes envolvidas na micropolítica do cotidiano escolar. A ordem do dia a dia perde sua naturalidade quando os atores começam a problematizar os jogos de forças presentes em cada desafio. Por outro lado, os professores também passam a se reconhecer como criadores de suas práticas docentes e do cotidiano institucional.

Segundo Bondia (2002), para além das tantas informações circulantes no mundo, a experiência constrói um novo "sentido no modo como configura uma personalidade, um caráter, uma sensibilidade ou, em definitivo, uma forma humana singular de estar no mundo, que é por sua vez uma ética (um modo de conduzir-se) e uma estética (um estilo)" (p. 27). Tendo o encontro universidade-escola como espaço privilegiado de experiment(ação), cremos que os tensionamentos e aberturas aí suscitados viabilizaram a construção de novas práticas efetivamente emergentes, em que ambos atores advindos, seja da universidade seja da escola, saíram transformados.

\footnotetext{
${ }^{6}$ Discussões presentes no Projeto Político Pedagógico do curso de Psicologia da Universidade Federal do Ceará, Campus Benfica.

${ }^{7}$ Ao final do ano, o programa de extensão TVEZ: Educação para o Uso Crítico da Mídia foi chamado e a desenvolveu um trabalho com alguns alunos para lançar um jornal impresso da escola.
} 


\section{Referências}

Aguiar, K. F., \& Rocha, M. L. (2007). Micropolítica e o exercício da pesquisa-intervenção: referenciais e dispositivos em análise. Psicologia: Ciência e Profissão, 27(4), 648-663. https://doi.org/10.1590/S1414-98932007000400007.

Bondia, J. L. (2002).Notas sobre a experiência e o saber de experiência. Revista Brasileira de Educação, (19), 20-28. https://doi.org/10.1590/S1413-24782002000100003

Coutinho, R. X., Folmer, V., \& Puntel, R. L. (2014). Aproximando universidade e escola por meio do uso da produção acadêmica na sala de aula. Ciência \& Educação (Bauru), 20(3), 765-783. https://doi.org/10.1590/1516-73132014000300016.

Dias, R. O. (2011). Pesquisa-intervenção, cartografia e estágio supervisionado na formação de Professores. Fractal: Revista de Psicologia, 23(2), 269-290. https://doi.org/10.1590/S1984-02922011000200004

Dias, R. O. (2012). Produção da vida nos territórios escolares: entre universidade e escola básica. Psicologia \& Sociedade, 24(spe), 67-75. https://doi.org/10.1590/S0102-71822012000400011

Dias, R. O. (2015). Pesquisa-Intervenção e formação inventiva de professores. Rev Polis e Psique, 5(2), 193-209. https:// doi.org/10.22456/2238-152X.53949

Foucault, M. (2004). A ordem do discurso:aula inaugural no Collège de France, pronunciada em 2 de dezembro de 1970. São Paulo: Loyola.

Freitas, Z. L., Carvalho, L. M. O., \& Oliveira, E. R. (2012). Educação de professores da universidade no contexto de interação universidade-escola. Ciência \& Educação (Bauru), 18(2), 323-334. https://doi.org/10.1590/S1516-73132012000200006.

Heckert, A. L. C., \&Rocha, M. L.(2012). A maquinaria escolar e os processos de regulamentação da vida. Psicologia \& Sociedade, 24(num esp.), p. 85-93. https:// doi.org/10.1590/S0102-71822012000400013

Kastrup, V. (2008). O Método da cartografia e os quatro níveis da pesquisa-intervenção. In L. Castro, V. L. Besset (Orgs.), Pesquisa intervenção na infância e juventude (pp. 465-489). Rio de Janeiro, RJ: Nau.

Kastrup, V (2010). O funcionamento da atenção no trabalho do cartógrafo. In E. Passos, V. Kastrup, \& L. Escóssia (Org.), Pistas do método da cartografia: Pesquisa-intervenção e produção de subjetividade (pp. 32-51). Porto Alegre, RS: Sulina.

Lourau, R. (2004). Uma apresentação da análise institucional. InS. Altoé (Org.), René Lourau: analista institucional em tempo integral (pp. 47-283). São Paulo, SP: Hucitec.

Lüdke, M., \& Boing, L. A. (2012). Do trabalho à formação de professores. Cadernos de Pesquisa, 42(146), 428451. https://dx.doi.org/10.1590/S0100-15742012000200007

Machado, A. M. (2014) Exercer a postura crítica: Desafios no estágio em psicologia escolar. Psicologia: Ciência e Profissão, 34(3), 761-773.https://doi.org/10.1590/1982-3703001112013

Marli, A. (2012). Políticas e programas de apoio aos professores iniciantes no Brasil. Cadernos de Pesquisa, 42(145), 112-129. https://doi.org/10.1590/S0100-15742012000100008

Miranda, L. L. (2015). Educação e mídia: O que a psicologia social tem a ver com isso?. In A. F. Lima, D. C. Antunes, \& M. G. A. Calegare. (Orgs.), Psicologia social e os atuais desafios ético-políticos no Brasil (pp. 36-50). Porto Alegre, RS: ABRAPSO.

Miranda, L. L. (2014). Uma câmera na mão e um dispositivo na cabeça: carta aos pesquisadores. In G. Tavares, M. Moraes, \& A. Bernardes (Orgs.), Cartas para pensar. Políticas de pesquisa em psicologia (pp. 77-88). Vitória, ES: EDUFES.

Miranda, L. L., Cysne, J., \& Alves Filho, J. A. (2016a). Juventude e mídia: Discutindo, criando, pesquisando. In L. L. F. Vieira, \& T. N. Queiroz (Orgs.), Metodologias participativas e mobilização psicossocial: Promoção da saúde e enfrentamento da violência sexual e de gênero (pp. 209-231). Recife, PB. Ed. UFPE.

Miranda, L. L., Oliveira, E., Shioga, J., Rodrigues, D. (2016b). Pesquisando com jovens na escola: Desafios da pesquisa intervenção em dois contextos escolares. Psicologia Escolar e Educacional, 20(2), 245-254. https://doi.org/10.1590/2175-353920150202958 
Montenegro, D., Miranda, L. L., Feitosa, G. L., Cardoso, N., Oliveira, P., Oliveira, T. (2016). Pesquisando com professores: A centralidade do diário de campo e da restituição numa pesquisa-intervenção. Revista de Psicologia,7(1), 81-93.

Moraes, M.(2014). Do pesquisar com ou de tecer e destecer fronteiras. In A. G.Bernardes, G. M. Tavares, \& M. Moraes (Orgs), Cartas para pensar políticas de pesquisa em Psicologia (pp. 131-138). Vitória, ES: Edufes.

Nacarato, A. M. (2016). A parceria universidade-escola: utopia ou possibilidade de formação continuada no âmbito das políticas públicas? Revista Brasileira de Educação, 21(66), 699-716.https://doi.org/10.1590/S141324782016216636

Patto, M. H. S.(1984).Psicologia e ideologia: Uma introdução crítica à psicologia escolar. São Paulo, SP: T. A. Queiroz.

Paulon, S. M. (2005). A análise de implicação como ferramenta na pesquisa- intervenção. Psicologia \& Sociedade, 17(3), 18-25. https://doi.org/10.1590/S0102-71822005000300003

Paulon, S. M., \&Romagnoli, R. C. (2010). Pesquisa-intervenção e cartografia: melindres e meandros metodológicos. Estudos e Pesquisas em Psicologia. 10(1), 85-102.

Sibília, P. (2012). Redes ou paredes: A escola em tempos de dispersão. Rio de Janeiro, RJ: Contraponto.

Luciana Lobo Miranda

Professora do Programa de Pós-graduação em Psicologia da Universidade Federal do Ceará, Fortaleza - CE. Brasil. E-mail: lobo.lu@uol.com.br

José Alves de Souza Filho

Mestre em Psicologia pela Universidade Federal do Ceará, Fortaleza - CE. Brasil.

E-mail: josefilhoss@gmail.com

Priscila Sanches Nery Oliveira

Graduada em Psicologia pela Universidade Federal do Ceará, Fortaleza - CE. Brasil.

E-mail: priscilasanchesnery@hotmail.com

Suzana Kérzia Rocha Bezerra Sousa

Graduada em Psicologia pela Universidade Federal do Ceará, Fortaleza - CE. Brasil.

E-mail: susousa20@gmail.com

Endereço para correspondência:

Programa de Pós-graduação em Psicologia da UFC

Profa. Dra. Luciana Lobo Miranda

Av. da Universidade, 2762, Benfica - CEP: 60.020-180 - Fortaleza/CE - Área 2 do Centro de Humanidades - Bloco

Didático Prof. Ícaro de Sousa Moreira.

Telefone: (85) 3366-7661 / 3366-7651. E-mail: lobo.lu@uol.com.br

Recebido 05/12/2017

Reformulado 12/03/2018

Aprovado 16/04/2018

Received 12/05/2017

Reformulated $03 / 12 / 2018$

Approved 04/16/2018 
Miranda, L. L., Souza Filho, J. A., Oliveira, P. S. N., \& Sousa, S. K. R. B. (2018). A Relação Universidade-Escola na Formação de Professores.

Recibido 05/12/2017

Reformulado $12 / 03 / 2018$

Aceptado 16/04/2018

Como citar: Miranda, L. L., Souza Filho, J. A., Oliveira, P. S. N., \& Sousa, S. K. R. B. (2018). A relação Universidade-Escola na formação de professores: Reflexões de uma pesquisa-intervenção.

Psicologia: Ciência e Profissão, 38(2), 301-315. https://doi.org/10.1590/1982-3703005172017

How to cite: Miranda, L. L., Souza Filho, J. A., Oliveira, P. S. N., \& Sousa, S. K. R. B. (2018). The University-School relationship in teacher training: Reflections of a research-intervention. Psicologia: Ciência e Profissão, 38(2), 301-315. https://doi.org/10.1590/1982-3703005172017

Cómo citar: Miranda, L. L., Souza Filho, J. A., Oliveira, P. S. N., \& Sousa, S. K. R. B. (2018). La Relación Universidad-Escuela en la formación de profesores: Reflexiones de una investigación-intervención. Psicologia: Ciência e Profissão, 38(2), 301-315. https://doi.org/10.1590/1982-3703005172017 